\title{
CENTRALISED MULTI-NATIONAL PRACTICES OF TRANSFER AND MANAGERIAL DISCREPANCIES: EVIDENCE FROM A ROMANIAN CALL CENTER
}

\author{
ZOLTAN MIHÁLY1
}

\begin{abstract}
This paper describes workplace dynamics in a call centre located in Romania, a subsidiary of a multi-national corporation (MNC). Positing a centralised practice transfer and global management strategy, the company relies exclusively on home-country decision makers. Placed within Romania's dependent economic profile alongside its deregulated employment relations, centralised managerial decisions create widespread organisational uncertainty with numerous hire and fire and downsizing procedures, followed by subsequent recruitment campaigns designed to replace the previously displaced workforce.
\end{abstract}

Keywords: multinational corporation; practice transfer; call centre; Romania

\section{Introduction}

Although Romania's economic profile is steadily reaching western EU levels in terms of export complexity (Ban, 2019; Ban and Adăscăliței, 2020), significant portions of its services sector persistently encompass low valueadded outsourcing and offshoring initiatives. While regional economic hubs (primarily Bucharest, Cluj-Napoca, Iasi and Timisoara) represent stark exceptions due to their diverse economic landscapes, customer support centres are still characterised by increased levels of instability: company mergers, corporate takeovers and capital flight. In the realm of organisational practices, these conditions can contribute to workplace ambiguities with significant effects on the workforce.

By focusing on an online retail MNC, the paper contributes to existing literature on multinational practice transfers and workplace management strategies situated within global value chains (GVCs) (Fernet et al., 2012;

1 Babeș-Bolyai University, zoltan.mihaly@ubbcluj.ro. 
Kristensen and Morgan, 2012; Harley, 2015; Welch and Bjorkman, 2015; Zhu and Morgan, 2018), highlighting their possibilities and constraints in Romania's dependent market economy. The primary argument lies in the contextual elements (mainly economic and legislative) that enable MNCs to engage in complex, yet erratic, management practices in their Romanian subsidiaries.

In contrast to Zhu and Morgan's (2018) depiction of IT companies, the studied company limits inter-firm collaborations along the supply chain, preferring to offshore various workflow elements. For example, customer support services are largely managed by Romanian offices, while manufacturing, logistics and retail operations are delegated to western European and Asian subsidiaries. Furthermore, despite the complex internal coordination requirements, the company assumes a centralised management scheme, relying on home-country office decisions, often leading to misinterpretation of global operation necessities. In turn, erroneous appraisal of global organisational activities imposes a volatile workplace. Namely, in Romanian offices, downsizing operations and hire and fire practices are exceedingly frequent. As is often the case, inconsistent decisions are followed by offsetting procedures, mainly recruitment campaigns destined to replace previously dismissed personnel.

Operating at the 'micro-organisational level' of MNC transfers (Ferner et al., 2006), the empirical data was collected using ethnographic methods: indepth interviews and participant observation sessions. Fieldwork was conducted over a 12-month period, intermittently, during 2018. The interviews, 10 in total, took place in informal settings, interviewees holding various positions in the company: manager, HR specialist, office administrator and customer support (CS) specialists. Participant observation sessions, as a full-time employee with a temporary work contract, ensued in two distinct 3-month periods, FebruaryApril and October-December. Consent was obtained from the managing bodies of the company, under the condition of full anonymity.

A reflexive approach is assumed, making use of Burawoy's (1998; 2000; 2009) extended case method. Coupled with a strand of literature aptly named comparative institutionalist theory (Cooke et al., 2018), the study embraces both direct engagement with the field site and subsequently extends its scope to transnational contingencies from a historical, sectoral and institutional level. Initial contact with the field site started via an acquaintance, who provided insider knowledge and later access to the workspace.

The paper starts out by constructing the theoretical framework of MNC practices transfer and positioning Romania's dependent market economy within existing writings. The case-study depiction begins with the studied MNCs dynamics in GVCs, highlighting its global reach on three continents and shifting position in the chain by virtue of internal accumulation strategies. 
Afterward, the narrative continues with the ramifications of centralised decisionmaking on HR practices and work management. Finally, assuming a first-person approach, the specific effects of the same practice transfers on employee wellbeing are presented.

\section{Context-dependence and MNC transfer practices}

Following numerous attempts to ease the 'shock of transition' from state capitalism to a global market economy in the first decade of the post-socialist period, Romania's liberal government instituted liberalisation initiatives under the guidance of World Bank and IMF experts. Fuelled by memories of its socialist past, the country's political establishment introduced an even more radical version of the neoliberal agenda than prescribed by global financial institutions (Ban, 2016).

Namely, the anticommunist discourse morally legitimised liberal policies while downplaying social policies. Furthermore, the anti-communist discourse also impacted the Romanian workforce. Attempts to negate unionisation initiatives and ideas of worker solidarity were placed in the same logic of communism versus democracy (Poenaru, 2017). The primary agenda was to increase employee subordination, stripping them of past work values (viewed as the socialist work ethic) and attempting to inscribe autonomy-based values adaptable to employer needs. These tendencies culminated with the deregulation of the Romanian labour market in 2011 (Varga and Freyberg-Inan, 2014). Amendments were made to the Labour Law, stressing the 'rigidity' problem reminiscent of socialism and the need for a flexible workforce suited to FDIs. Changes included additions for easing temporary employment, the possibility of dismissal in case of strikes and the substitution of unions by work councils. These circumstances implicitly contributed to the power inequalities in employment relations geared towards corporate incentives via state policies, while downplaying social measures.

The resulting economic trend materialised under what certain authors (Nolke and Vliegenthart, 2009; Tarlea and Freyberg-Inan, 2018) have called a "dependent market economy" (DME) of the neoliberal type, similar to the Baltic States (Bohle and Greskovits, 2012), consisting of a more radical marketoriented economy with reduced social implications. In more recent writings (Ban, 2019; Medve-Balint and Scepanovic, 2019; Vukov, 2020), the DME category is predominantly mobilised for depicting Romania's economic landscape. More specifically, the country is an outsourcing and offshoring site mainly for German and Austrian capital (Marin, 2006). As a result, between 2002 and 2010, the percentage of FDI from Romania's GDP increased from 10 to 43.9 percent, with 56 percent of investments aimed at the services sector. 
Predominantly endorsing least-cost strategies, the country's economic profile is characterised by export-oriented production situated in the GVCs of more complex products and services - with mounting evidence of increased export complexity (Ban and Adăscăliței, 2020) - and outsourced services. Making use of low-cost labour power engaged in low-value added operations, largely without the possibility of collective action, constitutes the 'conditions of emergence' (Freyssenet, 2009) for MNCs. As "work organisation is always contextdependent" (Elger and Smith, 2005: 7), organising day-to-day operations without limitations presents no drawbacks for employers. However, these circumstances can subject employees to unquestionable managerial decisions and lack of viable legal actions.

MNC practices implementation originating in the country of origin generally divergent in subsidiaries either due to the local context or, as Ferner et al. (2006) argue, the outcome of interactions between parent and host countries' national business systems. Thus, context-dependence exhibits various factors inhibiting or enabling various practice transfers and management strategies (Lane, 2008). The direction of transfers can also vary, as Chiang et al. (2019) adequately summarise, from forward (home to host country) to horizontal (between host country subsidiaries) and reverse (host to home country) conforming to MNC operational strategies. Furthermore, transfers can be standardised when stemming from centralised management and localised in the case of independent subsidiaries.

Borrowing from institutionalist theory, Kristensen and Morgan (2012) highlight the fluctuating organisational practices in contemporary capitalism. The constantly shifting realities of the global economy drives MNCs to experiment and adapt to market dynamics. Through 'firm-level experimentation', companies can consolidate their market positions and establish future expansion strategies. Albeit global dynamics represent the focal point of their study, particular attention should be given to liberal and dependent institutional establishments, where forms of experimentation can resemble hire and fire operations and unpredictable work environments as is the case in this study. Furthermore, even though Zhu and Morgan's (2018) critique of worker depictions in certain writings is justified (for example, Bair and Werner, 2015), in deregulated contexts, employee agency can be severely limited. Describing employees as 'objects' is arguably warranted in unfavourable circumstances from a legal point of view, coupled with a lack of local job opportunities or meaningful income alternatives (Mihaly, 2015; 2021).

Shifting focus to manufacturing, as Boyer and Freyssenet (2002) state, MNC value creation strategies converge in productive models surmising distinct product policies, organisation of production and national employment relations. 
Product policies are determined by the viability of products in various markets, while the organisation of production embraces the specific mode of manufacturing. Both are determined by host-country labour market characteristics. Certain features (corporate culture and work organisation) tend to be identical in host countries, while industrial relations are adapted to specific regulatory frameworks (Meardi et al., 2009). As is often the case, while home country regulations tend to be strict, subsidiaries are placed in deregulated contexts, such as those currently in Central and Eastern Europe. MNCs thus adapt managerial and productive practices to flexibility requirements, often transferring labour intensive processes to host-country facilities while also delegating managerial autonomy to these sites.

\section{The company's global dynamics}

The case study company is an online retailer, with business policies spanning over GVCs. Various sections of its transnational operations are allocated to different subsidiaries located in Europe and Asia. The company transfers practices from home country office to subsidiaries, although the specificities of these transfers vary according to operating requirements. For example, facilities in Romania are managed in accordance with operations in China, or vice-versa. Managerial decisions stemming from home-country offices take into account progress or regress in global affairs. Thus, personnel reductions in Romania can be the outcome of successful operations in China. Nonetheless, the home office functions differently compared to its subsidiaries, volatile management practices are designed and implemented exclusively in external facilities.

Global operations are centrally supervised by a home office managing body pertaining to various company departments. The diffusion of practices is standardised and oriented in a forward direction (Edwards, 1998), from homecountry offices to subsidiaries. Given Romania's deregulated context, few obstacles can dispute centralised managerial decisions, in contrast with Ferner et al.'s (2012) depiction of possible opposition from subsidiaries. This state of affairs is also influenced by the lack of a home-country delegate in subsidiaries, thus central managers lack a credible grassroots perspective.

The company's merchandise ranges from home and garden décor products to furniture and clothing. While products were initially sourced from other vendors, the majority of items are manufactured internally, with a significant expansion of its repertoire. According to data collected from the company's internal archives, customers originate from Europe, USA and Australia. Various regions are covered by promoting approximately two dozen online shopping 
platforms, with different brandings and website domains. Their online expansion can be traced via the establishment of said platforms. For example, in 2007, a German website was opened, 2008 a French one, from 2013 and onwards platforms for Austria, Greece, Spain, etc. In 2016, the company's domains reached 17 countries, including the USA.

New subsidiaries and departments also emerged on the backdrop of retail growth. The Romanian offices opened in 2016, tasked mainly with customer support operations, while logistics was off-shored to China. Global operations later included drop-shipment and marketplace options. Drop-shipment entails supplying other online retailers, mainly with furniture kits. In practice, dropshipping essentially reserves specific products in the supplier's warehouses, without needing to physically receive them. After the order is received by dropshipment client, they manage the shipping operations, even though the products are delivered from the drop-shipment supplier, the company in question. Marketplace operations entail product placement on the company's online platforms, external place-holding beneficiaries managing customer orders as if their own, in exchange for various placement fees in accordance with placed product values. In both cases, the studied MNC's position in GVCs changes as a result of drop-shipping and marketplace operations, assuming the role of supplier in the former and retail intermediary in the latter.

According to management documents, the main factors behind this accelerated expansion lie in market studies and extensive client feedback system implemented in online platforms. The company owns a single manufacturing facility in China destined primarily for furniture production, other types of commodities are assembled on per order basis or sourced from other vendors. However, the demand for garden and home furnishings far exceeds other types of products. Logistics operations are limited to each continent, mainly due to transportation costs, especially for large packages. As a result, "delivery zones" are disconnected from each other: products available in European warehouses are shipped only on the continent. Products are also selected based on consumption targets, price ranges and national or regional variation:

We advertise products exclusively online, without any physical stores, and customers cannot see any item in person. So, we have a few stocked warehouses, in Europe, other regions, China too, USA also. Thus, we have websites for every country we are present in. These websites have products destined for that nationality so to say, or for a specific customer target group. For example, products on the Romanian website cannot be found on Italian or French platforms (F, 35 years old, Operations Manager). 
Online orders are relayed to the nearest warehouse. Otherwise, logistics employees need to determine the optimal sourcing method and arrange transportation routes from other warehouses on the continent. In Europe, shipping routes are largely pre-determined and standardised seasonally. In the USA or Australia, product variety is reduced, transportation costs are significantly higher and sourcing possibilities limited. The company's headquarters is located in western Europe, adjacent to its largest warehouse, two other warehouses serve the America market, while another two are positioned in Australia. Table 1 contains further data.

Table 1.

Company information

\begin{tabular}{|l|c|}
\hline Employees (global) & 1400 \\
\hline Centers of operation (HQ and subsidiaries) & 13 \\
\hline Branded products & 23,000 \\
\hline Sales per day (average) & 20,000 \\
\hline $\begin{array}{l}\text { Packages shipped from largest warehouse per } \\
\text { day }\end{array}$ & 25,000 \\
\hline Road vehicles & 125 \\
\hline Online visits (all platforms, in 2017) & $\sim 50$ million \\
\hline
\end{tabular}

Data source: internal documents.

\section{Work management and organizational urgencies}

As mentioned, organisational practices are transmitted from homecountry offices. Inter-office communication is largely unidirectional, subsidiary managers lacking input in centralised decision-making. Assuredly, decisions shape the local organisational context, determining significant changes at office level. Furthermore, given Romania's deregulated employment relations favouring employers, managerial choices are freely implemented, with considerable impact on employees. Similarly, HR Specialists are thrust in the frontlines of remedying the aftermath of inconsistent decisions. These circumstances include urgent recruitment needs for specific customer support teams, often calling for improvised recruiting methods. 
The company's first facility in Romania opened in 2016, with 10 customer support employees, followed later that year by the second and third. The organisational structure is team-based, with two distinct categories: administrative-management personnel and customer specialists. While the former are the customary office administrators, HR specialists and management staff, the latter represent work teams grouped on different languages: English, German, Spanish, French, Finnish, Turkish, Romanian, Hungarian, etc. Each support team varies in size and designation in accordance with demand from different countries. For instance, orders from certain countries are less frequent or fluctuate seasonally (e.g. holiday season and the summer period), thus support employees with a reduced workload are relegated to other teams (mainly English or Romanian), based on their language skills. Moreover, the smallest office (15 employees) is dedicated exclusively for the German market.

The studied facility is the second largest in Romania, with approximately 100 employees, customer support employees covering 9 languages. Work contracts are mainly temporary, HR specialists inform employees of the possibility of further extension or permanent agreements after recruitment. The procedure was identical in my case as well, as a participant observer, an HR colleague telling me that:

there is a possibility of a permanent work contract, but we cannot guarantee it will happen. Everything depends on the workload and board of (homecountry) managers ( $F, 32$ years old, HR Specialist).

Work hours are predominantly full time. However, administrative personnel have added flexibility: clock-in and -out intervals are flexible, and working from home was possible for a limited number of days per month even before the pandemic. Conversely, customer support staff has a fixed 9-17 daily schedule with a one-hour lunch break. Employees from the same team are required to alternate break hours in order to answer potential customer calls accordingly.

Taking advantage of deregulated circumstances, the company applies numerous employment strategies, temporary contracts, student internship programs, and work from home arrangements during the pandemic period. While the practice is less intrusive than in the case of temporary work agencies in Central and Eastern Europe (Andrijasevic and Sacchetto, 2017), personnel management strategies are adapted according to centralised decision makers' evaluation. More often than not, events of mass dismissals are performed in a relatively short timeframe without repercussions for the employer.

The workplace centres around the customer support specialists, who occupy the largest area in the office. Employees are positioned on two sides of a divider, loosely separating different teams. Work desks are segmented once more on both sides of said divider with movable screens, destined to accurately partition of teams for specific languages. The operations manager is positioned at the left-most edge of the large divider, a vantage point for viewing employees 
on both sides. Noise cancelling headphones are mandatory for each employee in the central area. The administrative staff occupies adjacent offices along a hallway, while the kitchen and break rooms are situated next to lobby and floor entrance.

The recruitment process involves a number of standardised steps, following internal regulations. However, in essence, hiring boils down to passing a language (excepting native Romanian speakers) evaluation test on desired positions, prior experience and academic degrees are omitted:

I saw the job posting on OLX (popular Romanian advertising platform). I was unemployed at the time and needed a job, so I applied. A few days later I was contacted by an HR Specialist and invited to a one-on-one meeting in the office. The interview was short, few questions and done, I was hired (F, 28 years old, Customer Support Specialist, Romanian team).

After applied for various jobs, I finally found this one. It is a completely new sector for me, I would not have imagined working here, but it is an opportunity at least (F, 30 years old, Customer Support Specialist, Spanish team).

Shifting to an internal perspective, recruiters, at first, approach selected candidates with information about the company, the client services sector and their potential responsibilities as a customer support specialist. The ensuing language test is crucial in determining not only if the candidate has adequate spoken language competency level, but remuneration level as well. Financial offers are calculated based on language proficiency and candidate availability. For instance, a Finnish, German or French speaker would generally have higher pay compared to an English, Romanian or Hungarian speaker due to their availability nationally and locally.

As mentioned by an interviewee, job postings are advertised on various platforms: LinkedIn, OLX, or eJobs. Other postings target students, job-oriented groups on popular social media platforms are usually targeted. During urgencies, in the aftermath of personnel reductions, alternative recruitments methods are utilised. The depiction of a specific event exemplifies these circumstances. Throughout the summer period, an unexpected German speaker necessity arose. The precise origins are difficult to trace, however, a decision not unlike the ones usually relayed from the home-office was received and needed to be put in practice. Thus, the HR personnel posted job offers on the various university literature and language faculties and reached out to collaborating faculty departments in the effort of recruiting German-speaking students. Needless to say, it was a period of intensified work and heightened stress for the company's HR Specialists.

The referral system, a more stable recruitment procedure, is in place as well. Every newly hired employee is presented, during the initial onboarding session, with the possibility of recommending potential candidates. When new 
positions are opened, typically with specific language requirements, employees can propose acquaintances for hiring. After successfully passing the recruitment process and the three-month probation period (required by law), the recommending employee receives a bonus of $300 €$. In certain teams, the majority of employees are referrals. For example, locally, Finnish speakers are exceedingly scarce. Thus, the Finnish team is composed mainly of students (various generations recommended by an employee) from a specific specialisation.

Work tasks range from answering emails, online platform chat and customer calls. The variety of possible issues can also vary from product inquiries to quality complaints and warranty issues. During the introductory training, employees are presented with standardised procedures:

When employees join, they have an official 7-10 day training period. Usually, trainers provide instructions on issues encountered in teams employees will be part of. In practice, the training period is gradual, we start by only answering e-mails and chat messages, then we respond to calls. Later, if you are needed in other teams, only documentation is provided, without any formal training. If you have questions, you can ask your superior (F, 28 years old, Customer Support Specialist, Romanian team).

\section{Employee evaluations through the global chain of command}

The internal hierarchy consists of three distinct levels: customer support staff, team leaders and administrative-managerial staff. Customer support specialist and team leaders are subordinated to the operations manager, the highest-ranking local employee. The chain of command extends globally, with operations and logistics coordinated various high-ranking managers from China, while administrative staff from every Romanian office assists home-country managers.

Performance is measured via a percentage of customer issues, named 'tickets'. Customer support employees can visualise daily remaining tasks on their screens, each represented by orders with various issues. Tickets are divided into first- and second-line support. The former entailing hands-on contact with clients, warehouse staff and couriers. The latter requires assistance via e-mail or platform messaging. Furthermore, tasks can also range between pre-sales and after-sales - before and after an order has been placed - and seasonally - 'high' (usually from February to July) and 'low season' (August to January). These variables determine the difficulty and duration of work tasks:

The order is placed by customer on our websites. It cannot be confirmed via phone or e-mail as the only payment method is with credit card. We (Customer Support Specialists) do not even have access to financial information, only to an order number via email and a few other notifications in various stages: when it leaves the warehouse, location of the packages en route, etc. (M, 33 years old, former employee). 
Tasks are always determined seasonally. During high season, we have 15 tasks to resolve per hour and have to divide our time between first- and second-line tasks: when you respond to chat messages, when you handle phone calls...it is difficult. As we are during high season, we are regularly working over hours, even from home (F, 29 years old, Customer Support Specialist, Italian team).

Customer support evaluation criteria are split into quantitative and qualitative key performance indicators (KPI). Quantitative KPIs measure the previously mentioned tasks per hour, including time required for completing tasks during low- and high-season: minutes and seconds spent replying to messages, emails and phone calls. The duration of tasks is adjusted according to experience in the company: 0-3 months, 3-6 months and 6+ months. These variables serve to evaluate employees and classify productivity into four categories: very good, good, average and improvement. Qualitative KPIs serve two purposes: to determine to content of relayed messages compared to required templates and employee adaptability and evaluate employee attitude. The latter is quantified in proactivity, flexibility and work ethic, all categories measured via break period and work hours consistency alongside absenteeism.

Evaluations are performed by team leaders once per quarter, and consist of individual discussions based on the mentioned criteria. Conforming to evaluation outcomes, various improvement plans are compiled, salaries can be increased or bonuses provided:

Team-leaders collect information and after 3 months they offer feedback, what needs to be improved, needs to be done...based on these, you can have your salary increased, or remain with the same one and how to improve your work ( $F, 35$ years old, former employee).

\section{Procedures of uncertainty: downsizing and hire and fire}

In the first few weeks as an employee, the constant impression of impending organisational changes loomed. Various informal discussions also hinted to an upcoming decision from the home office. When expectations materialised, the decision - personnel reductions in two work teams - was perceived without astonishment, a fact evidencing the commonality of unstable organisational management. For instance, a prior downsizing procedure was carried out in another Romanian office a few years before, resulting in the simultaneous dismissal of 50 employees. A few months later, the same number positions were opened in the studied office. Management's reasoning was based on the company's rapid expansion, the downsizing was justified under the guise of strategic reorganisation. However, considering the identical labour costs and the added costs of a renewed recruitment effort, the pertinence of the decision comes into question. 
As mentioned, the depicted downsizing event started out as a rumor. Although initially limited to administrative personnel (and despite their efforts to confine the information), the news eventually turned into common knowledge. Doubtlessly, the work environment became tense, collective imagination revolved around the targeted individuals or teams. The operations manager was the only employee with precise information:

At a managerial level, the decision was gradual. We expected it somehow, but we were not informed until the day in question. Thus, we could only inform the employees on the same day as well. Management was aware of this ahead of time and we need to implement it. A 2-3-month announcement in advance would be welcomed. No one said anything, X just decided and said: we will fire them! Reorganise the department! Management comes up with decisions and we have to implement them, there is no choice: now they told our manager that until X month our office can have only X agents. They do not care how we do it, just do it (F, 27 years old, Recruiter).

The downsizing event unfolded in a streamlined manner. The head of operations called for a meeting one day before the procedure was destined to take place. Employees were informed about the company's issues and another impending personnel reduction episode that will affect two teams. The meeting lasted for no more than 10 minutes. Reactions varied from laughter and sarcastic remarks to concern and anxiety. After the general meeting, the members of the two teams were called into the meeting room and the dismissed employees were announced. In view of the company's history, the required paperwork for dismissals is prepared beforehand in the eventuality of sudden downsizing decisions. As a result, the selected employees were presented with the paperwork and asked to sign. The recruiter recalled the events:

It was not easy ... after every employee signed, I was the one there, alone with all of them. I had to calm them, when everyone was voicing their discontent ... I had to be emphatic and let them vent their frustration ... it was fine in the end (F, 27 years old, Recruiter).

The selection criteria for dismissed employees consisted of KPI indicators, the lowest ranking members from each team were named. Apart from this rationale, no other justification was offered by local, nor home-country managers. In the interview with the operations manager, the sole motive for the frequent hire and fire practices was the company's expansion in a fluctuating manner:

The customer support department is the most affected by these decisions, those employees are the most impacted...today you have X number of colleagues, you get to know them, then we go back to $\mathrm{X}$ number again. Today we expand teams there, then we move X team in another office. They (home office managers) proceed due to the business expansion, they reorganise a lot and change massively (F, 35 years old, Operations Manager). 
However, it is uncertain how the company strives to expand, as evidence of innovation is scarce. The idea of 'making things work' is also disputed by employees. Apart from the dwindling morale, discontent was voiced mainly due to the sudden unfolding of events, lack of communication and the increased work load for remaining employees. While the downsizing unquestionable had an effect on the company's expenditure, the previous workflow remained. Furthermore, as a direct side effect of the latest downsizing procedure, approximately 10 more employees voluntarily resigned. Thus, the personnel reduction tended to indicate the company's contraction, not expansion.

A few months after these chain of events, similar procedures occurred in other Romanian offices, pointing at a comprehensive transfer of practices on a national level. From the approximately 100 employees in Romania, less than half remained as a result of downsizing practices. Erroneous communication and centralised managerial decision can contribute to these shortcomings. The transfer of home-country practices, by all intents and purposes, lack systematic justification and are perceived as random decision unnecessarily destabilising the workplace.

The company's external reputation also comes in question during recruitment campaigns. General perception in the local labour market is that of a company in constant reorganisation, unstable, suited mostly for seasonal work or as an intermediary job. During my final days as an employee, recruiters struggled to re-configure affected work teams, needing to improvise various parttime and short-term arrangements, all while facing numerous refusals and negative feedback. On the other hand, the external reputation is mirrored by the internal one, although the general opinion resembles resignation and futility toward managerial decisions:

When you look at those empty chairs, you do not feel happy. They were, after all, colleagues of ours...and you hesitate to think if they are able to find another job, how they will pay rent or bank loans, how will they uphold their families...you automatically think that you can be in their place too and maybe this chair will once be empty...we need stability, to be able to somewhat relax (F, 28 years old, Customer Support Specialist, Romanian team).

\section{Conclusions}

The overall climate of uncertainty evidenced by interviewees and personal observation is determined by inconsistent centralised decisionmaking and their imposition as mandatory MNC practices in the host-country. Global operations are distributed to various off-shored facilities, each with their specific role in GVCs. Owing to the company's complex operational framework 
stretching over three continents, centralised decisions transferred to subsidiaries provoke widespread organisational changes with repercussions on the workforce and the MNCs external reputation.

By fixating on a Romanian subsidiary tasked with managing customer support operations, the paper contributes to existing works on corporate management practice transfers (Fernet et al., 2012; Kristensen and Morgan, 2012; Zhu and Morgan, 2018). The main point of contention is represented by host-country economic and legislative circumstances enabling a wide variety of organisational arrangements and management strategies culminating with frequent downsizing procedures. As the presented data indicates, the internal hierarchy mainly consists of work teams entrusted with solving product-related issues via e-mail, online messaging or phone calls. The operations manager is the highest-ranking employee and the sole recipient of home-country managerial decisions. Employee evaluations are performed quarterly using quantitative (tasks per hour) and qualitative (quality of services and employee discipline) KPIs, taking into account seasonal variation.

Organisational changes are common occurrence, with various downsizing events taking place in all Romanian offices. The primary justification resides in a corporate expansion narrative. However, as the data shows, the origins and means of organisational growth remain uncertain. Nevertheless, the managerial discrepancies residing in personnel reductions in an office followed by recruitment campaigns in another point to misaligned managerial decisions with significant repercussions for employees, partly due to centralised corporate practice transfers. Placed in a deregulated context, employees have limited means of counteracting managerial decisions or providing meaningful alternatives, thus perpetuating the existing status quo.

\section{REFERENCES}

Andrijasevic, R., and Sacchetto, D. (2017). 'Disappearing workers': Foxconn in Europe and the changing role of temporary work agencies. Work, Employment and Society 31(1), 54-70. doi:10.1177/0950017015622918

Ban, C. (2016). Ruling Ideas. How Global Neoliberalism Goes Local. New York: Oxford University Press.

Ban, C. (2019). Dependent development at a crossroads? Romanian capitalism and its contradictions. West European Politics 42(5), 1041-1068.

Ban, C., and Adăscăliței, D. (2020). The FDI-led Growth Regimes of the East-Central and the South East European Periphery. CBDS working paper. 26 June, 2020. Accessed 15 October, 2021. https://researchapi.cbs.dk/ws/portalfiles/portal/61037562/ cornel_ban_et_al_CBDS_working_paper_2020_2.pdf

Burawoy, M. (1998). The Extended Case Method. Sociological Theory 16(1), 4-33.

Burawoy, M. (2000). Global Ethnography: Faces, Connections, and Imaginations in a Postmodern World. Berkeley: University of California Press. 
Burawoy, M. (2009). The Extended Case Method Four Countries, Four Decades, Four Great Transformations, and One Theoretical Tradition. Berkeley: University of California Press.

Boyer, R., and Freyssenet, M. (2002). The Productive Models. The Conditions of Profitability. London, New York: Palgrave.

Bohle, D., and Greskovits, B. (2012). Capitalist Diversity on Europe’s Periphery. London: Cornell University Press.

Chiang, F.T., Lemański K.M., and Birtch T.A. (2017). The transfer and diffusion of HRM practices within MNCs: lessons learned and future research directions. The International Journal of Human Resource Management 28(1), 234-258. doi: 10.1080/09585192.2016.1246461

Cooke, F.L., Wood, G., Wang, M., and Veen, A. (2019). How far has international HRM travelled? A systematic review of literature on multinational corporations (20002014). Human Resource Management Review 29(1), 59-75. doi: 10.1016/j.hrmr. 2018.05.001

Edwards, T. (1998). Multinationals, labour management and the process of reverse diffusion: A case study. The International Journal of Human Resource Management 9, 696-709.

Elger, T., and Smith, C. (2005). Assembling Work: Remaking Factory Regimes in Japanese Multinationals in Britain. New York: Oxford University Press.

Harley, B. (2015). The one best way? 'Scientific' research on HRM and the threat to critical scholarship. Human Resource Management Journal, 25(4), 399-407.

Ferner, A., Quintanilla, J. and Sanchez-Runde, C. (2006). Introduction: Multinationals and the Multilevel Politics of Cross-National Diffusion. In: Ferner A, Quintanilla J and Sanchez-Runde C (eds) Multinationals, Institutions and the Construction of Transnational Practices. New York: Palgrave Macmillan, 1-23.

Ferner, A., Edwards, T., and Tempel, A. (2012). Power, institutions and the crossnational transfer of employment practices in multinationals. Human Relations 65(2): 163-187. doi:10.1177/0018726711429494

Freyssenet, M. (2009). Wrong Forecasts and Unexpected Changes: The World that Changed the Machine. In: Freyssenet M (ed) The Second Automobile Revolution. New York: Palgrave Macmillan, 7-37.

Kristensen, P.H., and Morgan, G. (2012). From Institutional Change to Experimentalist Institutions. Industrial Relations: A Journal of Economy and Society, 51: 413437. doi:10.1111/j.1468-232X.2012.00685.X

Lane, C. (2008). National capitalisms and global production networks: an analysis of their interaction in two global industries. Socio-Economic Review 6(2), 227260. doi:10.1093/ser/mwm010

Marin, D. (2006). A New International Division of Labour in Europe. Outsourcing and Offshoring to Eastern Europe. Journal of the European Economic Association 4(2-3), 612-622.

Meardi, G., Marginson, P., Fichter, M., Frybes, M., Stanojevic, M., and Tóth, A. (2009). Varieties of Multinationals: Adapting Employment Practices in Central Eastern Europe. Industrial Relations 48(3), 489-511. 
Medve-Bálint, G. and Scepanovici, V., (2019). EU funds, state capacity and the development of transnational industrial policies in Europe's Eastern periphery. Review of International Political Economy 27(5), 1063-1082.

Mihály, Z. (2015). The Making of Cheap Labour Power: Nokia's Case in Cluj. Studia UBB Sociologia, LX (1), 63-81.

Mihály, Z. (2021).Transnational transfer of lean production to a dependent market economy: The case of a French-owned subsidiary in Romania. European Journal of Industrial Relations January 2021. doi:10.1177/0959680120986781

Nolke, A., and Vliegenthart, A. (2009). Enlarging the Varieties of Capitalism: The Emergence of Dependent Market Economies in East Central Europe. World Politics 61(4), $670-702$.

Poenaru, F. (2017). Locuri comune. Clasă, anticomunism, stânga [Common places. Class, anticommunism, the left]. Cluj-Napoca: Tact.

Tarlea, S., and Freyberg-Inan, A. (2018). The Education Skill Trap in a Dependent Market Economy: Romania's Case in the 2000's. Communist and Postcommunist Studies 51(1), 49-61.

Varga M and Freyberg-Inan A (2014). Post-communist State Measures to Thwart Organised Labour: The Case of Romania. Economic and Industrial Democracy 36(4), 677-699.

Welch, D., and Björkman, I. (2015). The place of international human resource management in international business. Management International Review 55(3), 303-322.

Vukov, V. (2019). European integration and weak states: Romania's road to exclusionary development. Review of International Political Economy 27(5), 1041-1062.

Zhu, J., and Morgan, G. (2018). Global supply chains, institutional constraints and firm level adaptations: A comparative study of Chinese service outsourcing firms. Human Relations 71(4), 510-535. doi:10.1177/0018726717713830 